\title{
Um Estudo das Acurácias e Procedimentos de Medição de Alunos do Nível Médio Baseado em Duas Alternativas Pedagógicas
}

Osmar Henrique Moura da Silva

Carlos Eduardo Laburú

Ana Cláudia Força

\section{Resumo}

Este estudo faz uma avaliação dos resultados de recentes pesquisas, sendo uma quantitativa e outra qualitativa, respectivamente relacionadas às acurácias e procedimentos de medição de alunos do nível médio quando submetidos a dois distintos encaminhamentos pedagógicos em atividades empíricas que envolvem mensurações. As conclusões obtidas pela reunião desses resultados apoiam o entendimento de um desses encaminhamentos como método auxiliar mais vantajoso à iniciação de um processo instrucional dos conceitos de medição.

Palavras-chave: Atividade experimental, física, acurácia, conceitos de medição, estratégia pedagógica.

\section{Abstract}

High school student's study of accuracies and measurement procedures

\section{based on two pedagogical alternatives}

This study carries out an evaluation of recent quantitative and qualitative studies' results related to high school students' accuracies and measurement procedures when subjected to two separate educational activities involving empirical measurements. Conclusions originated from these results support the understanding that one of these activities represents a more advantageous auxiliary method for initiating a measurement concepts instructional process.

Keywords: Experimental activity, Physics, accuracy, measuring concepts, pedagogical strategy.

\section{Introdução}

A condução de atividades experimentais, quantitativas ou qualitativas, no ensino de ciências é dependente de alguma base epistemológica. Nesse contexto, designadas as orientações de ações e raciocínios dos alunos, muitas estratégias de ensino frequentemente têm se diferenciado por se fundamentarem ou no conhecido teste de hipóteses ou no emprego de um 
paradigma (inspirações de origem popperiana e kuhniana, respectivamente), haja vista que fundamentações positivistas tornaram-se mais criticadas na educação científica. No tocante à parte experimental que abrange as mensurações, uma preocupação seminal envolve o processo instrucional acerca da medição, sendo que a habilidade do aluno para lidar com a confrontação entre teoria(s) e evidência implica saber estabelecer relações entre variáveis, processar dados e usá-los para sustentar uma conclusão. Dentro dessa preocupação, investigações em educação científica (SILVA \& LABURÚ, 2013; LABURÚ et al., 2010; LABURÚ \& BARROS, 2009; BUFFLER et al., 2001; KIRSCHNER, 1992; COELHO, 1993; JOURNEARX \& SERÉ, 1994; LUBBEN \& MILLAR, 1996; ALLIE et al., 1998) têm indicado que os alunos inicialmente se apresentam com um conjunto de ideias problemáticas acerca da medição em experimentos quantitativos, que reúne a coleta, o processamento e a comparação de medidas. Na literatura, as noções prévias à instrução dos alunos encontram-se agrupadas no denominado paradigma Pontual e confrontam-se com as cientificamente estabelecidas, reunidas no chamado paradigma de Conjunto (SILVA \& LABURÚ, 2013; LABURÚ et al., 2010; LABURÚ \& BARROS, 2009; BUFFLER et al., 2001). Diante disso, a princípio, a solução ideal estaria no emprego de uma elaboração instrucional sobre medição que considerasse esses 'paradigmas'. Objetivando auxiliar numa elaboração instrucional nesse sentido, estabelece-se aqui um estudo reflexivo sustentado pelo cruzamento de informações de recentes pesquisas educacionais (LABURÚ et al., 2012; LABURÚ et al., 2013) relacionadas à medição.

\section{Paradigma Pontual vs. paradigma de Conjunto}

As concepções alternativas dos alunos pertencem a uma importante linha de pesquisa em educação científica (GILBERT \& SWIFT, 1985; MORTIMER, 1996, p. 21). Em relação ao conceito de medição, Buffler et al. (2001) e Allie et al. (1998) destacam-se por inicialmente divulgarem um forte conjunto de ações e raciocínios dos alunos, que puderam ser entendidos como conservando um paralelo com o conceito kuhniano de paradigma (KUHN, 1977), aqui denominado paradigma Pontual, ${ }^{1}$ e que se opõe àquele destinado ao ensino, denominado paradigma de Conjunto.

No paradigma Pontual, o valor de uma medição é expresso por um único valor devido aos raciocínios que levam à compreensão de que apenas uma única medida é suficiente, e que há um, e somente um, verdadeiro valor a ser encontrado, inexistindo a necessidade de se obterem outros resultados num experimento. Toda medida obtida é vista como independente das demais, sendo cada uma suficiente para se tomarem decisões, desprezando-se, em razão disso, qualquer

${ }^{1}$ A designação pretende conotar um grupo de crenças, valores, técnicas, etc., compartilhados pelos alunos quando ponderam sobre medição. Maiores esclarecimentos sobre as razões da formação do paradigma Pontual podem ser vistos em Laburú \& Barros (2009).

R. B. E. C. T., vol 8, núm. 3, mai-ago.2015 ISSN - 1982-873X

DOI: Em andamento. 
tipo de combinação de uma com as outras. Diferente de um resultado pertencente a um intervalo de possíveis valores, a medida é imaginada como tendo apenas um único valor. Se, porventura, ainda ocorrerem outras medidas, as decisões subsequentes são tomadas restringindo-as em reflexões particulares, quais sejam: seleção do valor recorrente, posição numa tabela (extremos ou equidistantes), comparação feita valor a valor, etc. Disto decorre a falta de sentido em se tirarem médias de uma amostra e, por conseguinte, em se determinar a sua correspondente incerteza. Fundamentalmente, o que está por detrás do paradigma Pontual é uma inerente concepção errônea de que em toda atividade empírica inexistem erros experimentais, uma vez que qualquer medição deve fornecer uma medida exata e única.

Em contraposição, o paradigma de Conjunto caracteriza-se pela noção de que o valor numérico de uma grandeza física experimental somente é determinado pela resultante de uma reunião de dados experimentais. Há, sim, pelo referencial da teoria de erros, a consideração da existência de um "valor verdadeiro ou valor alvo" (VUOLO, 1992, p. 38) bem definido para toda grandeza física experimental e que pode ser caracterizado por meio de um modelo do fenômeno físico. Todavia, esse valor é sempre desconhecido pela ocorrência de erros experimentais inevitáveis na realização de uma medição. Isto independe da melhoria de métodos e instrumentos de medida (ibid.), mesmo que evidenciada a busca desse valor como objetivo final de um processo de medição de uma grandeza física experimental. Logo, é coerente realizar uma quantidade de medidas para se obter uma distribuição que congregue os valores encontrados e considerados, estabelecendo uma estimativa do espalhamento numérico do valor resultante para avaliar quão adequada é a grandeza. Estatisticamente, indica-se uma estimativa de quão afastado o resultado pode estar do valor verdadeiro (HELENE \& VANIN, 1981, p. 15). Na consideração de haver apenas erro estatístico, a melhor informação para representar esse valor verdadeiro (ou valor alvo) é alcançada pela combinação da maior quantidade possível de medidas. Perante uma coleção de dados, a média aritmética expressa estatisticamente esse desejado valor verdadeiro, no entendimento de que ele possivelmente coincida com, ou esteja próximo do, valor médio calculado, cuja estimativa de proximidade é probabilística e fornecida pelo desvio padrão da média (ibid., 17).

\section{Cruzamento de recentes resultados de pesquisas educacionais em medição}

Pelo exposto até o momento e tendo a intenção de caminhar para uma reflexão auxiliadora à problemática educacional acerca da medição, os resultados de duas pesquisas (AUTORES, 2012; AUTORES 2013) são explorados. Essas pesquisas diferenciam-se em objetivos e conclusões na coincidência de confrontarem as duas mesmas alternativas pedagógicas e em iguais atividades empíricas envolvendo mensurações. A simples diferença metodológica entre essas duas alternativas pedagógicas das pesquisas foi como segue. Enquanto por uma alternativa 
se informara previamente os alunos sobre o valor da grandeza física a ser encontrado na atividade experimental, pela outra eles permaneceriam desconhecendo este valor durante a mesma atividade experimental. A primeira dessas alternativas, analogamente à inspiração kuhniana da estratégia didática de Millar (1987), ${ }^{1}$ esteve, enquanto proposta, tão somente a fazer com que o aluno possuísse uma expectativa do valor da medida, permitindo que ele soubesse o valor a ser encontrado no experimento. Na situação de uma expectativa prévia do resultado, a equivalência educacional com a "luz" de uma compreensão teórica prévia de Millar (ibid.) implica que a atividade prática deva se ajustar e se conformar para o aparecimento do valor experimental então almejado. Essencialmente, é por meio dessa expectativa do resultado experimental, estabelecida por uma alternativa pedagógica, mas não pela outra, que as duas pesquisas direcionaram as atividades experimentais aos alunos, atrelando seus interesses investigativos, que foram: análise, entre as alternativas pedagógicas empregadas, da qualidade da medida dos alunos em termos de acurácia (LABURÚ et al., 2012); diferenciação dos comportamentos relativos às ações e raciocínios dos alunos entre aqueles que se submeteram a uma alternativa pedagógica e os que se submeteram à outra (LABURÚ et al., 2013).

${ }^{1}$ Que, por sua vez, ampara-se no modelo epistemológico de Kuhn (1977 e 1987). Millar (1987) defende que as observações dos aprendizes em atividades empíricas sejam guiadas por paradigmas previamente conhecidos (opondo-se às estratégias de ensino por descoberta ou hipotético-dedutivas). Nesse entendimento, a realização de experimentos escolares deveria expor um paradigma (ibid., p. 114), justificada no seguinte argumento: a concordância entre teoria e experimento significa apenas concordância razoável, pois quase sempre a aplicação de uma teoria física implica alguma aproximação e, por conseguinte, não se espera que a teoria produza resultados totalmente precisos ou exatos, mas uma concordância possível com os dados (KUHN, 1977, ps. 229 e 231). Sendo a teoria condutora dos refinamentos, inventos e aproximações teóricas (ibid., ps. 239 e 244), considera-se que os dados experimentais sempre embutem dúvidas e incertezas quando se veem isolados de um paradigma que os analise e os enquadre, ou seja, encontram-se inviabilizadas adequadas inspeções de resultados de medições feitas sem um prévio conhecimento teórico. Assim, da mesma forma que, para Kuhn (1977 e 1987), um paradigma define o campo quantitativo em questão, para Millar (1987), realizar um experimento escolar é expor um paradigma e não descobrir um conhecimento ou checar hipóteses. Millar entende ser mais necessário priorizar e devotar um maior tempo para negociar, discernir e avaliar os resultados de um experimento escolar frente à teoria ensinada, do que consumir excessivo tempo em ficar executando a atividade empírica (ibid., p. 115). E uma maneira de observar se um aprendiz efetuou corretamente um experimento é inspecionar se os seus resultados obtidos concordam com as expectativas esperadas da teoria aprendida. Esta conclusão educacional é fortalecida em Hodson (1994) e Gil-Pérez (1986).

R. B. E. C. T., vol 8, núm. 3, mai-ago.2015 ISSN - 1982-873X

DOI: Em andamento. 
Para realizar um cruzamento dos resultados dessas duas pesquisas, selecionam-se alguns dados de alunos (representativos de uma amostra investigada de 80 alunos $^{1}$ ) do primeiro ano do nível médio de um colégio da rede pública do estado do Paraná, organizados em duas turmas, uma formando um grupo experimental (GE) e outra um grupo controle (GC), cada qual com subgrupos de dois integrantes, codificados respectivamente de GE1 e GE2, e de GC1 e GC2. O grupo controle $(\mathrm{GC})$ abrange os alunos submetidos à atividade experimental com valor de medida inicialmente desconhecido e, os demais, que realizaram a atividade por orientação do valor da medida previamente informado, integram o grupo experimental (GE). Nas duas pesquisas, ambos os grupos de alunos realizaram a mesma atividade experimental, que foi determinar a densidade de um óleo de cozinha, ${ }^{2}$ utilizando um béquer de $600 \mathrm{ml}$, um tubo de vidro para colocar o óleo e uma balança de precisão analógica de décimos de grama. Todos os alunos foram instruídos a usar a balança e medir o volume do óleo (quantidade que ficou a critério de cada subgrupo), para então calcular a densidade através da expressão $d=m / V$. Apenas os GEs foram informados do valor tabelado da densidade do óleo $(\mathrm{d}=0,9166 \mathrm{~g} / \mathrm{ml}$ ). As atividades experimentais foram videogravadas e as falas dos alunos, transcritas e analisadas. Essas falas foram decompostas quando havia alguma interrupção/pausa ou nova enunciação, excluindo-se aquelas sem contribuição à pesquisa. $\mathrm{Na}$ análise, essas falas (especificadas em cada subgrupo como ditas por A1 e/ou A2) e as da professora (P) foram colocadas entre aspas e em itálico. Nas falas entre parênteses e na forma não itálica, aparecem termos ou comentários do pesquisador, com a intenção de aumentar o entendimento do que fora transcrito. Vale mencionar que, nos trabalhos, uma nova medida foi assim considerada toda vez que os alunos alteravam a massa ou o volume do óleo ao realizarem novos cálculos, sem necessariamente trocarem o conjunto 'óleo mais béquer'.

Em termos quantitativos relacionados à acurácia, a tabela 1 expõe duas linhas com as medidas fornecidas por 20 subgrupos (10 subgrupos do GE e 10 subgrupos do GC, totalizando os 40 alunos) e mais duas linhas contendo os respectivos desvios dos valores dessas medidas em relação ao valor alvo fornecido (valor tabelado de 0,9166 g/ml). São dez desvios de cada grupo, pelos quais se calcularam duas médias gerais, uma do GE e uma do GC, para efeitos comparativos

${ }^{1}$ Como se verá mais à frente, é feita uma seleção dos resultados de 40 alunos (LABURÚ et al., 2012) e outra seleção dos resultados de 20 alunos (LABURÚ et al., 2013). Em verdade, embora o presente estudo aglomere resultados das duas pesquisas mencionadas, ele se caracteriza mais como uma divulgação representativa do ocorrido numa pesquisa maior, de pós-graduação stricto sensu (FORÇA, 2012), da qual elas surgiram.

${ }^{2}$ Uma das pesquisas (LABURÚ et al., 2012) também averiguou as acurácias das medidas relativas a uma atividade de determinação da aceleração da gravidade local.

240 DOI: Em andamento.

R. Bras. de Ensino de C\&T 
de maior proximidade em relação ao valor alvo (isto é, de maior acurácia), levando em conta o teste estatístico $t$ de student. ${ }^{1,2}$

Tabela 1 (LABURÚ et al., 2012, p. 2503-4)

\begin{tabular}{|c|c|c|c|c|c|c|c|c|c|c|}
\hline & \multicolumn{10}{|c|}{ Valores das medidas para a densidade do óleo } \\
\hline $\mathrm{E}$ & ,8858 & 9273 & ,9121 & ,906 & ,9128 & 9033, & 915 & 9158, & 896 & 9175, \\
\hline C & 8823 & 9223, & 8918, & 9768 & 8215, & 9245, & ,882 & 8865 & 8915, & 8895 \\
\hline & \multicolumn{10}{|c|}{ Desvios absolutos dos valores das medidas em relação ao tabelado $(0,9166 \mathrm{~g} / \mathrm{ml})$} \\
\hline $\mathrm{E}$ & 0308, & 0107, & 0045 & 0106, & 0038, & 0133 & 0016, & 0008, & 0206 & 0009 \\
\hline C & 0343, & 0057, & ,0248 & ,0602 & 0951, & 0079, & 0346 & 0301 & ,0251 & 0271 \\
\hline
\end{tabular}

Pelo indicado na tabela 1, há confiança estatística de $99 \%^{3}$ em se afirmar uma diferença significativa entre a média dos desvios absolutos do grupo experimental (GE) ( $M=0,00976$ ) e a média dos desvios absolutos do grupo de controle $(G C)(M=0,03962)$. Diante disso, e apoiados em outros resultados semelhantes, LABURÚ et al. (2012) concluíram que os alunos com conhecimento prévio do valor da medida estatisticamente tendem a encontrar a medida com um menor desvio e, portanto, alcançam maior acurácia do dado experimental.

No entendimento dos motivos que levam ao aumento da acurácia dos alunos quando antecipadamente lhes é informado o valor experimental da medida, faz-se aqui uma seleção de resultados de análises dos comportamentos dos mesmos, então divulgados em LABURÚ et al.

${ }^{1}$ Todos os alunos tiveram liberdade em proceder com a repetição ou não da experiência para selecionar ou não uma medida entre outras, e mesmo fornecer uma medida final por meio de uma média entre algumas medidas consideradas.

${ }^{2} O$ teste aplicado à análise das variâncias (teste $F ; \alpha=0,05$ ) dos valores dos grupos (valores com distribuição normal) de cada turma concluiu uma heterogeneidade em ambos os casos, admitindo prosseguir com o uso particular do teste t para variâncias homogêneas.

${ }^{3}$ Teste $t$ uni-caudal $\left(t_{\text {cal }}=-3,54 ; \alpha=0,01\right)$ para amostras independentes.

R. B. E. C. T., vol 8, núm. 3, mai-ago.2015 ISSN - 1982-873X

DOI: Em andamento. 
(2013) e Força (2012). A tabela 2 expõe, para cada subgrupo, ${ }^{1}$ o tempo de envolvimento na atividade experimental e a quantidade de medidas coletadas, servindo esses parâmetros para o prosseguimento do tratamento qualitativo ao caso.

Tabela 2 (LABURÚ et al., 2013)

\begin{tabular}{|ccc|ccc|}
\hline $\begin{array}{c}\text { Grupo de } \\
\text { Controle }\end{array}$ & $\begin{array}{c}\text { Quantidade } \\
\text { de Medição }\end{array}$ & $\begin{array}{c}\text { Tempo } \\
\text { gasto }\end{array}$ & $\begin{array}{c}\text { Grupo de } \\
\text { Experimental }\end{array}$ & $\begin{array}{c}\text { Quantidade } \\
\text { de Medição }\end{array}$ & Tempo gasto \\
\hline GC1 & 1 & $9^{\prime} 17^{\prime \prime}$ & GE1 & 9 & $52^{\prime} 33^{\prime \prime}$ \\
GC2 & 1 & $10^{\prime} 15^{\prime \prime}$ & GE2 & 12 & $67^{\prime} 20^{\prime \prime}$ \\
GC3 & 2 & $22^{\prime} 33^{\prime \prime}$ & GE3 & 1 & $10^{\prime} 24^{\prime \prime}$ \\
GC4 & 1 & $10^{\prime} 25^{\prime \prime}$ & GE4 & 2 & $16^{\prime} 36^{\prime \prime}$ \\
GC5 & 1 & $9^{\prime} 40^{\prime \prime}$ & GE5 & 6 & $39^{\prime} 54^{\prime \prime}$ \\
\hline MÉDIA & 1,2 & $12^{\prime} 26^{\prime \prime}$ & MÉDIA & 6 & $37^{\prime} 28^{\prime \prime}$ \\
\hline
\end{tabular}

Em média, os alunos do GE despenderam mais tempo para a realização da atividade experimental, e com mais repetições do procedimento de coleta de medidas, que os integrantes do GC. Conforme LABURÚ et al. (2013), "isto se justifica por um conjunto de comportamentos apresentados pelos GEs que não foram identificados nos GCs, como maior cautela ao repetir a coleta da medida, maior número de diálogos e reflexões a respeito dos procedimentos efetuados e dos resultados obtidos." Uma síntese comparativa desses comportamentos é realizada abaixo.

Em geral, os diálogos estabelecidos entre os alunos do GC centraram-se muito mais em como utilizar o material e realizar os cálculos que os do GE, não se podendo destacar reflexões a respeito dos procedimentos e resultados encontrados. Os integrantes do GC1 realizaram apenas uma medição para declararem o valor da densidade do óleo encontrado: "0,8918 g/ml" (A2). Ao serem questionados pela professora ("Vocês estão satisfeitos com esse valor? Confiam nesse valor?"), disse A1: "Acredito que sim." E deram por finalizado o processo de medição logo após terem obtido o valor de uma única medida ("Concluíram sua medição?" (P); "Sim" (A1 e A2)). Comportamento semelhante ocorreu nos alunos do GC2 (que diretamente forneceram o valor de "0,9245") e nos alunos do GC4, quando questionados pela professora acerca do valor obtido. No caso, estes últimos responderam: "0,8" (A2) e "... 0,8823 é o valor da densidade mais certo aqui

${ }^{1}$ Para não delongar o que se pretende indicar, a tabela 2 expõe uma seleção de resultados de metade dos subgrupos da tabela 1 , resultados estes representativos daqueles que totalizam a amostra investigada de 80 alunos (FORÇA, 2012).

242 DOI: Em andamento.

R. Bras. de Ensino de C\&T 
da calculadora professora... só isso professora?" (A1). Para estes alunos do GC2 e GC4, notou-se que o processo de medição estava concluído. Os dois alunos do GC5 também assumiram o valor para a densidade do óleo com apenas uma medição ("Deu 0,882" (A1)), levantando no final a coincidente pergunta de um dos subgrupos anteriores, através da qual se percebe 0 entendimento do aluno de cumprimento da tarefa: "É só isso professora?" (A1). Esses comportamentos observados, representativos da maioria dos integrantes do grupo controle, condizem com os esperados do paradigma Pontual. Já os alunos do GC3 obtiveram duas medidas, mostrando discórdia na decisão entre elas. Quando questionados se estavam satisfeitos com o primeiro valor ("Deu 0,8915" (A2)), A1 manifestou-se: “Pode medir para verificar de novo?" Dessa conduta adotada ("Tá... repete pra gente ver" (A2)) de verificar a ocorrência do primeiro valor (prevista no paradigma Pontual), eles demonstraram dúvida ao concluírem o cálculo da segunda medida ("Deu 0,877... um pouco menos!" (A1)). Nessa situação, notou-se inicialmente cada um optando por um valor, sendo que A1 alegou que o erro estava na primeira medida por tê-la realizado com um excesso de óleo, enquanto que $A 2$ havia admitido o contrário. Logo se percebeu que A2 mostrou-se mais contundente em sua decisão ("Eu continuo com essa daqui!"), ficando A1 por aceitar a decisão do parceiro e declarar que o valor para a densidade do óleo era o da primeira medida. ${ }^{1}$ Verificou-se que, embora poucos, os diálogos restringiram-se a como realizar os cálculos e a obter esclarecimentos de como operar a balança. (LABURÚ et al., 2013)

Diferentemente, os integrantes do GE evidenciaram uma natural característica ${ }^{2}$ deles de coletarem mais medidas, comportamento este desencadeado pela reação verificada de frustração ${ }^{3}$ com o primeiro resultado obtido, por compará-lo com o 'aguardado' valor alvo. ${ }^{4}$ Uma interpretação plausível dessa ocorrência procedimental está na naturalidade de tal insatisfação (com o resultado inicial) em potencializar uma sensação de necessidade de correção por repetição do feito, estimulada por uma reflexão imediata dos alunos sobre o que ocorreu diante do inesperado. Neles, a princípio, surgem suposições de algum erro sistemático que poderia ser

${ }^{1}$ Mesmo com uma inicial discórdia, percebeu-se que a realização de uma nova medida não foi o caminho tomado para resolvê-la, prevalecendo o desejo do término da tarefa de um deles por acordar com o outro.

${ }^{2}$ Exclusividade do emprego da estratégia que gera uma expectativa de obtenção de determinado valor experimental, ora informado previamente.

${ }^{3}$ No sentido de conflito cognitivo.

4Exemplos: GE1 - [" ... Ah... 0,888... ficou meio longe hein!" (A1); "Verdade!" (A2)]; GE2 - [“Aí deu meio estranho (0,8813333)" (A1); "Eu acho que deu errado isso ai" (A2)]; GE4 - ["Não... chegou perto? Será que a gente mediu errado (o valor de 0,876)?" (A2); "Deu aproximado mesmo, achei que ia dar um pouco mais" (A1)]; GE5 - ["É... (o valor) tá bem fora” (A1)].

R. B. E. C. T., vol 8, núm. 3, mai-ago.2015 ISSN - 1982-873X

DOI: Em andamento. 
consertado e que, por essa intuitiva conduta, ocasiona uma sucessiva repetição da coleta de dados com atenção direcionada à melhora do resultado experimental em procedimentos que julguem necessário refazer. ${ }^{1}$ Por fim, perante uma coleção de dados, eles acabaram por processar um valor para a densidade do óleo, selecionando-o por maior proximidade do valor alvo, por ser a medida procurada. Mais detalhadamente, houve a particularidade dos alunos do GE1, logo no início, de terem avaliado o valor de "0,9273" (A1) impróprio ("Aí acho que não professora... mede você ali na balança para ver, usando o mesmo material, e coloca uma gota de óleo só pra gente ver" (A1)); mas, depois das comparações, o escolheram para responder o problema. No GE2, os diálogos e reflexões, gerados tanto pela 'meta' que sentiam os alunos de alcançarem o valor alvo como pela discórdia com alguns valores encontrados, os levaram a se tornarem mais cautelosos à proporção que repetiam as medições, o que os conduzindo a fornecerem um resultado com maior acurácia ("Vamos deixar 0,9121" (A2)). No GE3, teve-se a situação ocasional em que eles, na primeira medida, inverteram a razão da massa pelo volume, encontrando o valor de "1,09194..." (A1), mas que foi em seguida corrigida por A2, que declarou o valor de "0,9158". Embora essa ação somente fora possível pela referência que eles tinham do valor correto, o subgrupo GE3 exemplifica um caso incomum que prejudica o emprego da estratégia e demonstra sua limitação, necessitando, portanto, de uma intervenção do professor. Isto aconteceu porque a primeira medida quase coincidiu com o valor esperado quando realizaram a correção do cálculo ("Deu bem o valor aproximado" (A2); “ ... é, fez certinho" (A1)), o que os estimulou a finalizar o processamento com a medida inicial, ação que vai ao encontro do paradigma Pontual. Quanto ao GE4, mesmo com a realização de apenas duas medidas, viu-se que a segunda delas ("0,9128" (A2)) acabou gerada ${ }^{2}$ por influência da estratégia de permitir que eles reconhecessem a possibilidade de terem errado na obtenção da primeira (" 0,876 " (A1)). Esta reação se diferenciou da maioria das do grupo controle (GC1, GC2, GC4 e GC5), que terminaram o processo de medição

${ }^{1}$ Exemplos: Subgrupo GE1 - ["Ah... eu acho que (o erro) foi na hora de medir, eu acho! ... o volume do óleo... será? Acho que na hora de medir não fica totalmente em cima do zero" (A1)]; Subgrupo GE2 - ["Olha 'meu'... cada vez dá um valor na balança 'cara"” (A1); "A medida que vocês acharam? Da balança?" (P); "É porque o valor toda hora muda" (A2); "Eu acho que passou bem pouquinho. Mas passou. Mas pode ser aqui também, com menos óleo... a medida que a gente tá vendo tá errada?" (A1); "Vê certinho!" (A1); " ... retira (o óleo) com a caneta pra não colocar muito. Calma aí! Deixa eu ver de novo" (A1)]; Subgrupo GE4 - [“Aumentar a quantidade de óleo... retirar (descontar) a massa do Becker..." (A2)]; Subgrupo GE5 - ["Os trezentos eu acho que está certo... e se colocasse um pouquinho mais... só mais um pouquinho... agora deu" (A1); "Você está marcando no lugar errado... tem que descer mais um pouquinho" (A2)].

${ }^{2}$ Foi selecionada com melhor acurácia, sendo admitida pela persistência de A2 prosseguir com mais cautela ("Dessa vez nós medimos com mais atenção"). 
logo na primeira medida, considerando todos igualmente submetidos à típica questão da professora: "Encontraram o valor da densidade?" Já o subgrupo GE5 apresentou uma reflexão diferenciada acerca de um erro de cálculo ocorrido na primeira medida, e a professora se viu tentada a promovê-la no sentido de fazê-los perceber a inversão que fizeram da razão massa por volume. ${ }^{1}$ Após a correção do cálculo, obtendo 0,931 , notou-se que A2 avaliou o resultado pensando na existência de fatores que pudessem influenciar o processo de medição ("É o cálculo ou ter pesado errado alguma coisa (quantidade de óleo a mais)"). Decidiram então refazer a medida, ${ }^{2}$ logo outra para verificar/comprovar, ${ }^{3}$ e mais outra, ${ }^{4}$ totalizando seis medidas realizadas. Desse total coletado, finalizaram o processamento da medição ao selecionarem a medida com maior proximidade do valor tabelado ("Colocaria o valor que mais se aproximava... o que mais se aproximou foi esse aí, porque os outros aqui em cima deu 0,890 (A1)"; "O que mais se aproximou foi o último $(0,9175)$... é porque como ali está aproximadamente, o valor exato mesmo não vai dar, é aproximadamente" (A2)). (ibid.)

${ }^{1} \mathrm{O}$ diálogo restringido a perguntas que dela partiram assim ocorreu: "Encontraram o valor da densidade? Que valor vocês encontraram?" (P); "Sim, 267,6" (A1 e A2); “A densidade com valor de 267,6... qual a unidade da medida utilizada?" (P); "Foi grama... nós medimos em grama. Grama por ml" (A1); "Mas o que vocês me dizem do resultado?" (P); "Aquela densidade que está lá é de quantos gramas?" (A2); "Aquele valor (o tabelado) é a densidade do óleo" (P). Na confrontação dos valores $A 1$ afirmou: "É... (o valor) tá bem fora!".

2 "Quer refazer" (A1).

${ }^{3}$ Desse momento em diante, verificou-se que a postura deles foi de maior cautela, reflexão e diálogo a respeito dos procedimentos adotados, como mostram os comentários: "O que será que está errado aqui?... O(s) trezentos eu acho que está certo... e se colocasse um pouquinho mais... só mais um pouquinho... agora deu" (A1); "Não tem que ser aí 'ô'... você está marcando no lugar errado... tem que descer mais um pouquinho" (A2).

${ }^{4}$ Nesse sentido, os alunos decidiram repetir algumas vezes o processo de medição, ora trocando o conjunto (béquer + óleo), ora ajustando o volume ou a leitura da balança ("Eu acho que passou um pouquinho o óleo... tinha que estar em cima da risca... mas passou um pouquinho" (A2); "A diferença vai estar aqui... eu acho que passou um pouco... você não acha? Um pouquinho de nada, mas passou. Agora eu acho que está certo... Agora sim" (A1)). E ao se depararem novamente com um valor que não era igual ao tabelado ("Deu 0,924" (A1)), A2 argumentou ("Tem coisa errada aí... tá errado aí. O óleo está certo, o béquer também pesou certo. Será que não é a balança que está roubando?") e concluiu: "Não tem como (alcançar o valor tabelado)". 


\section{Discussão geral dos resultados e reflexão educacional}

Os integrantes do grupo controle, com exceção do GC3, contentaram-se com as únicas medidas coletadas (particulares de cada subgrupo) e com elas finalizaram suas medições. Especialmente no GC3, a tentativa frustrada dos alunos de obterem a primeira medida, ao objetivarem comprová-la na repetição, não conduziu em mais tentativas, cuja concepção de medida única somada com uma ansiedade de término da tarefa constituiu o fator influente para a decisão das medidas. Tais observações indicam que a estratégia didática dos alunos desconhecerem o resultado experimental os mantém com comportamentos cujas ações e raciocínios são exclusivos do paradigma Pontual.

Os integrantes do grupo experimental, com exceção do GE3, mostraram-se insatisfeitos com suas primeiras medidas coletadas e evidenciaram o interesse na busca de outros resultados, realizando repetições do processo de coleta. O distinto caso do GE3, em conformidade com o paradigma Pontual, exemplifica a situação mais incomum de a primeira medida ser interpretada pelos alunos como o valor esperado, o que, devido à coincidência do valor obtido com o tabelado, induziu-os a finalizar o processo de medição na primeira medida. Já os outros quatro subgrupos do GE, ainda que tivessem permanecido com concepções do paradigma Pontual, ${ }^{1}$ evidenciaram comportamentos diferenciados e favoráveis aos fins instrucionais que visam o paradigma de Conjunto, quais sejam: melhor avaliação de um resultado na comparação de valores via aperfeiçoamento das medições graças a algum novo ajuste a ser realizado; maior exploração da noção da existência de erros inerentes ao processo de medição, devido à persistência focada nas repetições; maior envolvimento no manuseio dos equipamentos e ponderações acerca das atitudes a proceder, pensando em explicações sobre o que estaria influenciando os resultados das medidas; correções de erros de cálculos, notados quando, por exemplo, grandezas das expressões ou unidades foram invertidas ou trocadas.

Entrelaçando essas análises gerais de comportamentos com os níveis de acurácia da tabela 1, a princípio, os dados apresentados podem inferir que a baixa acurácia dos valores fornecidos pelo grupo controle vincula-se à ausência da repetição da atividade experimental, necessidade não sentida pelos integrantes deste grupo por mostrarem-se satisfeitos com a primeira e única medida coletada, assim expondo claramente um dos comportamentos do paradigma Pontual. Entretanto, o que se pode afirmar é que, na hipótese menos provável desses alunos adotarem uma postura de repetirem medidas e as conflitarem, ${ }^{2}$ sem o direcionamento do

1 Segundo Autores (2013), o momento instrucional não tinha o objetivo de mudar essas concepções.

${ }^{2}$ Ultrapassando o que se encontrou no GC3.

246 DOI: Em andamento.

R. Bras. de Ensino de C\&T 
valor a ser obtido experimentalmente, a medida mais recorrente seria a escolhida. ${ }^{1}$ Nesse caso, naturalmente, nas reflexões estariam despercebidos os erros aleatórios e percebidos os erros sistemáticos (não propriamente com esse termo), os quais os alunos entendem, pelo paradigma Pontual, que, caso corrigidos, encontrar-se-iam valores iguais nas demais medidas divergentes. Logo, em geral descaracterizada a necessidade de repetição de medidas do grupo controle pela ausência da informação do valor alvo, uma previsão otimista de comportamento pela hipótese acima, ${ }^{2}$ pois não se pode afirmar pelos dados investigados, seria de resultados com melhoria de precisão e não de acurácia, no caso de um improvável procedimento espontâneo, gerando várias medidas. Assim sendo, o cruzamento aqui estabelecido dos resultados quantitativos e qualitativos indica que o benefício de se direcionarem as reflexões dos alunos para um valor alvo está em instigar ajuizamentos mais condizentes que desencadeiem noções acerca dos procedimentos e da existência de erros experimentais, o que justifica o benefício educacional estabelecido pela estratégia que proporciona a melhoria da acurácia. Esta reunião das análises permite salientar que a estratégia que parte do conhecimento prévio do valor experimental a ser obtido, mesmo que em termos pragmáticos seja mais demorada, ${ }^{3}$ apresenta-se em termos educacionais em benefício sobre a sua rival quando confrontadas. O critério que leva a esse julgamento está no grau da qualidade e confiabilidade da informação no âmbito da medição, sendo a primeira estratégia desencadeadora de uma inicial tomada de consciência dos alunos de erros experimentais, sejam os de tendência (erros sistemáticos) ou de precisão (erros aleatórios), incorporados no conceito de acurácia que qualquer instrução formal sobre medição deveria considerar. Referente à correção dos erros experimentais, os dados analisados indicam de modo qualitativo que a estratégia de fornecer o resultado a ser medido privilegia o refinamento da medida por adoção de maiores cautelas durante as repetições. Isto na proporção que se estimula a tomada de consciência relativa à dificuldade de se obter o valor tabelado em razão de erros experimentais que tenderam a ser percebidos como não podendo ser eliminados, conflitando, de certa forma, com a exatidão sobrevinda da noção do paradigma Pontual que os alunos já têm.

\footnotetext{
${ }^{1}$ Buffler et al. (2001).

${ }^{2}$ De acordo com o paradigma Pontual (ibid.).

${ }^{3}$ Pela tabela 2, o tempo da atividade pode, em média, prolongar-se por cerca de três vezes mais. Vale observar que, na comparação estabelecida, as duas estratégias mantiveram-se numa conduta exclusivamente construtivista, pela qual se excluiu a relação transmissão-recepção de informações entre professor e aluno, inviabilizando, assim, a passividade deste e o processo educacional centrado na ação docente. A professora, então, se limitou a poucas perguntas e, como participante, a acompanhar a ação dos alunos na atividade experimental.
}

R. B. E. C. T., vol 8, núm. 3, mai-ago.2015 ISSN - 1982-873X

DOI: Em andamento. 
Devido ao fato de a estratégia fornecer o valor alvo como referência ao aluno, cabe ressaltar ser natural que ele objetive conseguir esse resultado como entendimento de boa execução da tarefa. Todavia, o professor precisa estar atento para que não haja a simples manipulação de valores de grandezas por parte do aluno a fim de atingir o valor solicitado, situação esta que se pondera como de não participação na atividade proposta.

\section{Considerações finais}

A literatura tem postulado que alunos sem alguma instrução formal acerca de procedimentos de medição comportam-se com ações e raciocínios baseados no paradigma Pontual. Vale destacar, como parte do núcleo central desse paradigma, o comportamento comum de se limitar a uma única medida coletada durante a medição. Em relação a esse aspecto crucial, as reflexões do presente estudo permitem inferir que, mesmo sem qualquer instrução formal, a estratégia conduzida por meio da expectativa prévia do valor a ser encontrado experimentalmente revelou-se estimuladora de uma não aparente tendência natural dos alunos de coletarem mais medidas para a melhoria da acurácia. Essa contribuição, e mais o que foi dito logo na introdução do trabalho, implica numa segunda observação acerca das inserções de atividades didáticas que se baseiam costumeiramente ora em teste de hipóteses, ora em aplicação de um paradigma. Ou seja, são preferíveis estratégias instrucionais que partam de atividades que busquem a determinação de constantes ou comparação de hipóteses, todas com resultados antecipadamente conhecidos pelos alunos; isto, de forma geral, na consideração dos favorecimentos que se discutiu serem obtidos e que ressaltam comparativamente este método auxiliar como mais vantajoso à iniciação de um elaborado processo instrucional dos conceitos de medição que abranjam o aprendizado do paradigma de Conjunto. A oportunidade de o aluno ter passado pela estratégia de ensino de valores conhecidos, em que o professor pode abrir a possibilidade de levantar noções do paradigma de Conjunto a partir do incômodo produzido pelas concepções do paradigma Pontual, é que torna rico e mais prudente o emprego de atividades práticas que envolvam mensurações na procura de valores desconhecidos, como as de teste de hipóteses ou as que estudem possíveis covariações entre grandezas físicas, visto que nelas já se pode falar na necessidade de obter várias medidas devido às incertezas experimentais para decisão da melhor hipótese ou da lei entre grandezas físicas.

\section{Referências}

ALLIE, S., BUfFLER, A. LOVENESS, K., CAMPBELL, B. \& LUBBEN, F. First year physics students' perceptions of the quality of experimental measurements. International Journal of Science Education, v. 20, n. 4, p. 447-459, 1998. 
BUfFLER, A., ALLIE, S., LUBBEN, F. CAMPBELL, B. The development of first year physics students' ideas about measurement in terms of point and set paradigms. International Journal of Science Education, v. 23, n. 11, p. 1137-1156, 2001.

COELHO, S. M. Contribution à l'étude didatique du mesurage en physique dans l'enseignement secondaire: description et analyse de l'activité intelectuele et pratique des élèves et des enseignants. These de Doctorat, Université de Paris. (1993).

FORÇA, A. C. Estratégia de ensino para o aumento de acurácia das medidas experimentais no ensino médio. Dissertação de mestrado apresentada ao programa de pós-graduação da Universidade Estadual de Londrina (PR) para a obtenção do título de Mestre em Ensino de Ciências e Educação Matemática (2012).

GIL-PÉREZ, D. La metodología científica y la enseñanza de las ciências: unas relaciones controvertidas. Enseñanza de las Ciencias. Barcelona, v. 4, n. 2, p. 111-121, 1986.

GILBERT, J.K. \& SWIFT, D.J. Towards a Lakatosian analysis of the Piagetian and alternative conceptions research programs. Science Education. V. 69, n. 5, p. 681-696 (1985).

HELENE, O, A. M.; VANIN, V. R. Tratamento estatístico de dados experimentais em física experimental. Editora Edgard Blücher Ltda, 2a edição, São Paulo (1981).

HODSON, D. Hacia un Enfoque Más Crítico del Trabajo de Laboratorio. Enseñanza de las Ciencias, v. 12, n. 3, p. 299-313, 1994.

JOURNEAUX, R. SÉRÉ, M. G. Traitement stat istique des incertitudes en physique: problèmes scientifiques et didatiques. European Journal Physics, v. 15, p. 266-292, 1994.

KIRSCHNER, P. A. Epistemology Practical Work and Academic Skills in Science Education. Science \& Education, v. 1 v p. 273-299, $1992 . \quad$ Disponível em: http://link.springer.com/content/pdf/10.1007\%2FBF00430277. Último acesso: 06/12/2013.

KUHN, T. S. A função da medida na ciência. In: A tensão essencial. Biblioteca de Filosofia Contemporânea, Edições 70, Lisboa, Portugal, 223-273, 1977.

KUHN, T. S. A estrutura das revoluções científicas. Editora Perspectiva: São Paulo (1987).

LABURÚ, C. E.; BARROS, M. A. Problemas com a compreensão de alunos em medição: razões para a formação do paradigma Pontual. Investigações em Ensino de Ciências. V. 14, n. 2, p. 151-162, 2009.

LABURÚ, C. E.; FORÇA, A. F.; SILVA, O. H. M. Uma proposta de estratégia pedagógica para iniciação aos conceitos de medição por avaliação de dois métodos alternativos. ALEXANDRIA (Revista de Educação em Ciência e Tecnologia), v. 6, p. 197-211 (2013). 
LABURÚ, C. E.; SILVA, O. H. M.; FORÇA, A. C. Acurácia na retirada da medida instigada por uma estratégia de ensino de orientação kuhnina. Revista Brasileira de Ensino de Física. v. 34, n. 2 (2012).

LABURÚ, C. E.; SILVA, O. H. M.; SALES, D. R. Superações conceituais de alunos do ensino médio em medição a partir de questionamentos de uma situação experimental problemática. Revista Brasileira de Ensino de Física. V. 32, n. 1 (2010).

LUBBEN, F. \& MILLAR, R. Children's ideas about the reliability of experimental data. International Journal of Science Education, v. 18, n. 8, p. 955-968, 1996.

MILLAR, R. Towards a Role for Experiment in the Science Teaching Laboratory. Studies in Science Education, v. 14, p. 109-118, 1987. Disponível em: http://www.tandfonline.com/doi/abs/10.1080/03057268708559941\#preview. Último acesso: 06/12/2013.

MORTIMER, E. F. Construtivismo, mudança conceitual e ensino de ciências: Para onde vamos? Investigações em Ensino de Ciências. V. 1. p. 20-39 (1996).

SILVA, O. H. M.; LABURÚ, C. E. Um encaminhamento didático fundamentado na formulação de perguntas como auxílio ao processo educacional de medição. Revista Brasileira de Pesquisa em Educação em Ciências, v. 13, p. 195-213 (2013).

VUOLO, J. H. Fundamentos da teoria de erros. Edgard Blucher Ltda. São Paulo (1992).

Osmar Henrique Moura da Silva; Departamento de Física - UEL

Carlos Eduardo Laburú; Departamento de Física - UEL

Ana Cláudia Força; Colégio Estadual Tereza Cristina, Colorado - PR 